\title{
Therapeutic Apheresis
}

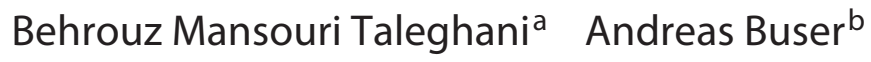 \\ a University Clinic of Hematology and Central Hematology Laboratory, Division of Transfusion Medicine, \\ Bern University Hospital, Inselspital, Bern, Switzerland; begional Blood Transfusion Service Swiss Red Cross Basel, \\ and Department of Hematology, University Hospital Basel, Basel, Switzerland
}

Our last issue of Transfusion Medicine and Hemotherapy with focus on "therapeutic apheresis" has been published 7 years ago, and the editorial started with: "Therapeutic (hem)apheresis (TA) using automated blood processing equipment is a highly developed technique to selectively deplete, exchange, replace, or at least manipulate particular cellular or soluble blood constituents in a broad panel of different diseases. Starting almost 100 years ago by Abel and co-workers in 1914 [1], it still continues to expand as the pathomechanisms of new and old disease entities are elucidated, confirming 'old' indications or revealing new rationales for the application of TA" [1]. The phenomenon of an incremental pace of continued rise of knowledge is unquestionably also true for this field of medicine. While, for example, 95 pages were needed for the "2010 ASFA guidelines" [2], the current version of the guidelines had to be extended to 184 pages [3]. This reflects the growing quality and quantity of evidence supporting the use of TA in various diseases and patients, in order to relieve symptoms (symptomatic therapy) or even save lives. The present issue of Transfusion Medicine and Hemotherapy again includes contributions of experts for TA evidenced by their own experience and/or the available literature.

First, Worel et al. [4] further contribute significantly in this context by summarizing the recommendations for TA of the section "Preparative and Therapeutic Hemapheresis" of the German Society for Transfusion Medicine and Immunohematology (DGTI). They emphasize and support a careful evaluation of the indication, balancing risks and benefits. We strongly recom- mended this article for all colleagues involved in TA the included table, listing current indications and including category and grade of recommendation, may be of particular interest.

Stuessi et al. [5] have focused their review on red blood cell exchange/depletion. While appreciated beyond controversy as an efficient therapeutic modality for lowering the hematocrit or transfusing without increasing the hematocrit or causing iron overload, specific studies/evidence on erythrocytapheresis are scarce. Therefore, this concise review is particularly valuable for understanding the current state of knowledge in red blood cell TA procedures.

Finally, Skorupka et al. [6] report their retrospective monocentric analysis, analyzing the visual outcomes of steroid-refractory optic neuritis patients treated with plasma exchange. Their study demonstrates significant improvements of visual acuity with plasma exchange in a cohort of 18 patients with acute, steroid-refractory optic neuritis. Despite the small sample size, their data clearly support the (early) use of plasma exchange in steroid-refractory optic neuritis with a favorable safety profile.

Taken together, the editors are convinced that the papers of this issue of Transfusion Medicine and Hemotherapy covering general as well as specific aspects of TA present the experience of experts on their field and will be very valuable for the concerned units in terms of a practical and scientific support for patients' treatment planning.

\section{KARGER}

(C) 2019 S. Karger AG, Basel 


\section{References}

1 Mansouri Taleghani B, Strasser E. Therapeutic Hemapheresis. Transfus Med Hemother. 2012 Aug;39(4):232-3.

2 Szczepiorkowski ZM, Winters JL, Bandarenko N, Kim HC, Linenberger ML, Marques $\mathrm{MB}$, et al.; Apheresis Applications Committee of the American Society for Apheresis. Guidelines on the use of therapeutic apheresis in clinical practice-evidence-based approach from the Apheresis Applications Committee of the American Society for Apheresis. J Clin Apher. 2010;25(3):83-177.
3 Padmanabhan A, Connelly-Smith L, Aqui N, Balogun RA, Klingel R, Meyer E, et al. Guidelines on the Use of Therapeutic Apheresis in Clinical Practice - Evidence-Based Approach from the Writing Committee of the American Society for Apheresis: The Eighth Special Issue. J Clin Apher. 2019 Jun;34(3):171-354.

4 Worel N, Mansouri Taleghani B, Strasser E. Recommendations for Therapeutic Apheresis by the Section "Preparative and Therapeutic Hemapheresis" of the German Society for Transfusion Medicine and Immunohematology (DGTI). Transfus Med Hemother. 2019; 46(6). https://doi.org/10.1159/000503937.
5 Stuessi G, Buser A, Holbro A. Red Blood Cells - Exchange, Transfuse or Deplete. Transfus Med Hemother. 2019;46(6). https://doi. org/10.1159/000504144.

6 Skorupka N, Miclea A, Jolwiec KA, Bocksrucker C, Kamber N, Mansouri Taleghani B, et al. Visual Outcomes of Steroid-Refractory Optic Neuritis with Plasma Exchange - a Retrospective Monocentric Analysis. Transfus Med Hemother. 2019;46(6). https://doi. org/10.1159/000504027. 